\title{
Controlling Chemical Reactions by Short, Intense Mid-Infrared Laser Pulses: Comparison of Linear and Circularly Polarized Light in Simulations of $\mathrm{ClCHO}^{+}$ Fragmentation
}

\author{
Xuetao Shi, Bishnu Thapa, Wen Li and H. Bernhard Schlegel* \\ Department of Chemistry, Wayne State University, Detroit, Michigan 48202, United States
}

\section{Supporting Information}

\section{Full citation for the development version of the Gaussian suite of programs:}

Frisch, M. J.; Trucks, G. W.; Schlegel, H. B.; Scuseria, G. E.; Robb, M. A.; Cheeseman, J. R.; Scalmani, G.; Barone, V.; Mennucci, B.; Petersson, G. A.; Nakatsuji, H.; Caricato, M.; Li, X.; Hratchian, H. P.; Izmaylov, A. F.; Bloino, J.; Zheng, G.; Sonnenberg, J. L.; Hada, M.; Ehara, M.; Toyota, K.; Fukuda, R.; Hasegawa, J.; Ishida, M.; Nakajima, T.; Honda, Y.; Kitao, O.; Nakai, H.; Vreven, T.; Montgomery Jr., J. A.; Peralta, J. E.; Ogliaro, F.; Bearpark, M. J.; Heyd, J.; Brothers, E. N.; Kudin, K. N.; Staroverov, V. N.; Kobayashi, R.; Normand, J.; Raghavachari, K.; Rendell, A. P.; Burant, J. C.; Iyengar, S. S.; Tomasi, J.; Cossi, M.; Rega, N.; Millam, N. J.; Klene, M.; Knox, J. E.; Cross, J. B.; Bakken, V.; Adamo, C.; Jaramillo, J.; Gomperts, R.; Stratmann, R. E.; Yazyev, O.; Austin, A. J.; Cammi, R.; Pomelli, C.; Ochterski, J. W.; Martin, R. L.; Morokuma, K.; Zakrzewski, V. G.; Voth, G. A.; Salvador, P.; Dannenberg, J. J.; Dapprich, S.; Daniels, A. D.; Farkas, Ö.; Foresman, J. B.; Ortiz, J. V.; Cioslowski, J.; Fox, D. J. Gaussian Development Version, H.35; Gaussian, Inc.: Wallingford, CT, USA, 2015.

\section{Trajectory Classification}

a) Trajectories with unphysical charge fluctuation during laser pulse: If Mulliken charge on any of the atoms changes from $+0.9(-0.9)$ to $-0.9(+0.9)$ within one laser cycle (23.5 fs), the trajectory is discarded.

b) Classification of trajectories into reaction channels:

1. Channel 1 (H dissociation): $\mathrm{C}-\mathrm{H}>2.2 \AA$ and $\mathrm{C}-\mathrm{Cl}<3.36 \AA$

2. Channel 2 (Cl dissociation): $\mathrm{C}-\mathrm{H}<2.2 \AA$ and $\mathrm{C}-\mathrm{Cl}>3.36 \AA$

3. Channel $3(\mathrm{HCl}+$ dissociation): $\mathrm{C}-\mathrm{H}>2.2 \AA, \mathrm{C}-\mathrm{Cl}>3.36 \AA$ and $\mathrm{H}-\mathrm{Cl}<2.54 \AA$

4. Channel 4 (Multi-dissociation): $\mathrm{C}-\mathrm{H}>2.2 \AA, \mathrm{C}-\mathrm{Cl}>3.36 \AA$ and $\mathrm{H}-\mathrm{Cl}>2.54 \AA$

5. Channel 5 (Non-dissociation): $\mathrm{C}-\mathrm{H}<2.2 \AA$ and $\mathrm{C}-\mathrm{Cl}<3.36 \AA$

(Note: The bond lengths used here are twice their equilibrium bond lengths) 
Some tests with alternative laser field conditions:

Table S1. Branching ratios for the dissociation of $\mathrm{ClCHO}^{+}$interacting with different types of left circularly polarized laser pulses.

\begin{tabular}{|c|c|c|c|c|}
\hline \multirow{2}{*}{ Polarization } & \multirow{2}{*}{$\begin{array}{l}\text { Field strength } \\
\text { (au) }\end{array}$} & \multicolumn{3}{|c|}{ Branching ratio } \\
\hline & & $\mathrm{Cl}+\mathrm{HCO}^{+}$ & $\mathrm{H}+\mathrm{ClCO}^{+}$ & $\mathrm{HCl}^{+}+\mathrm{CO}$ \\
\hline Left circular (trapezoid shape laser) & 0.06 & $30 \%$ & $47 \%$ & $23 \%$ \\
\hline Left circular (cosine shape laser) ${ }^{a}$ & 0.06 & $64 \%$ & $17 \%$ & $19 \%$ \\
\hline Left circular ( $\pi / 2$ initial phase $)^{b}$ & 0.06 & $38 \%$ & $43 \%$ & $19 \%$ \\
\hline Left circular ( $\pi / 4$ initial phase $)^{c}$ & 0.06 & $34 \%$ & $46 \%$ & $20 \%$ \\
\hline
\end{tabular}

${ }^{a} 400$ trajectories; ca. $16 \%$ did not dissociate. ${ }^{b} 400$ trajectories; ca. $9 \%$ did not dissociate. ${ }^{c} 200$ trajectories; ca. $10 \%$ did not dissociate.

Table S2. Average total energy absorbed by $\mathrm{ClCHO}^{+}$interacting with different types of left circularly polarized laser pulses.

\begin{tabular}{|c|c|c|}
\hline \multirow[b]{2}{*}{ Polarization ${ }^{a}$} & \multirow[b]{2}{*}{ Field Strength (au) } & Total energy (kcal/mol) \\
\hline & & $\begin{array}{c}\text { All } \\
\text { Channels }\end{array}$ \\
\hline Left circular (trapezoid shape laser) & 0.06 & $89.3 \pm 40.759 .1 \pm 25.194 .4 \pm 35.3119 .2 \pm 41.0$ \\
\hline Left circular (cosine shape laser) & 0.06 & $52.1 \pm 11.748 .4 \pm 11.2 \quad 55.3 \pm 8.2 \quad 61.8 \pm 9.3$ \\
\hline Left circular ( $\pi / 2$ initial phase) & 0.06 & $75.0 \pm 33.658 .3 \pm 23.181 .1 \pm 32.0 \quad 95.3 \pm 39.0$ \\
\hline Left circular ( $\pi / 4$ initial phase) & 0.06 & $83.1 \pm 37.964 .3 \pm 27.589 .3 \pm 36.6100 .5 \pm 42.8$ \\
\hline
\end{tabular}

${ }^{a}$ see footnotes of Table S1 for trajectory details 


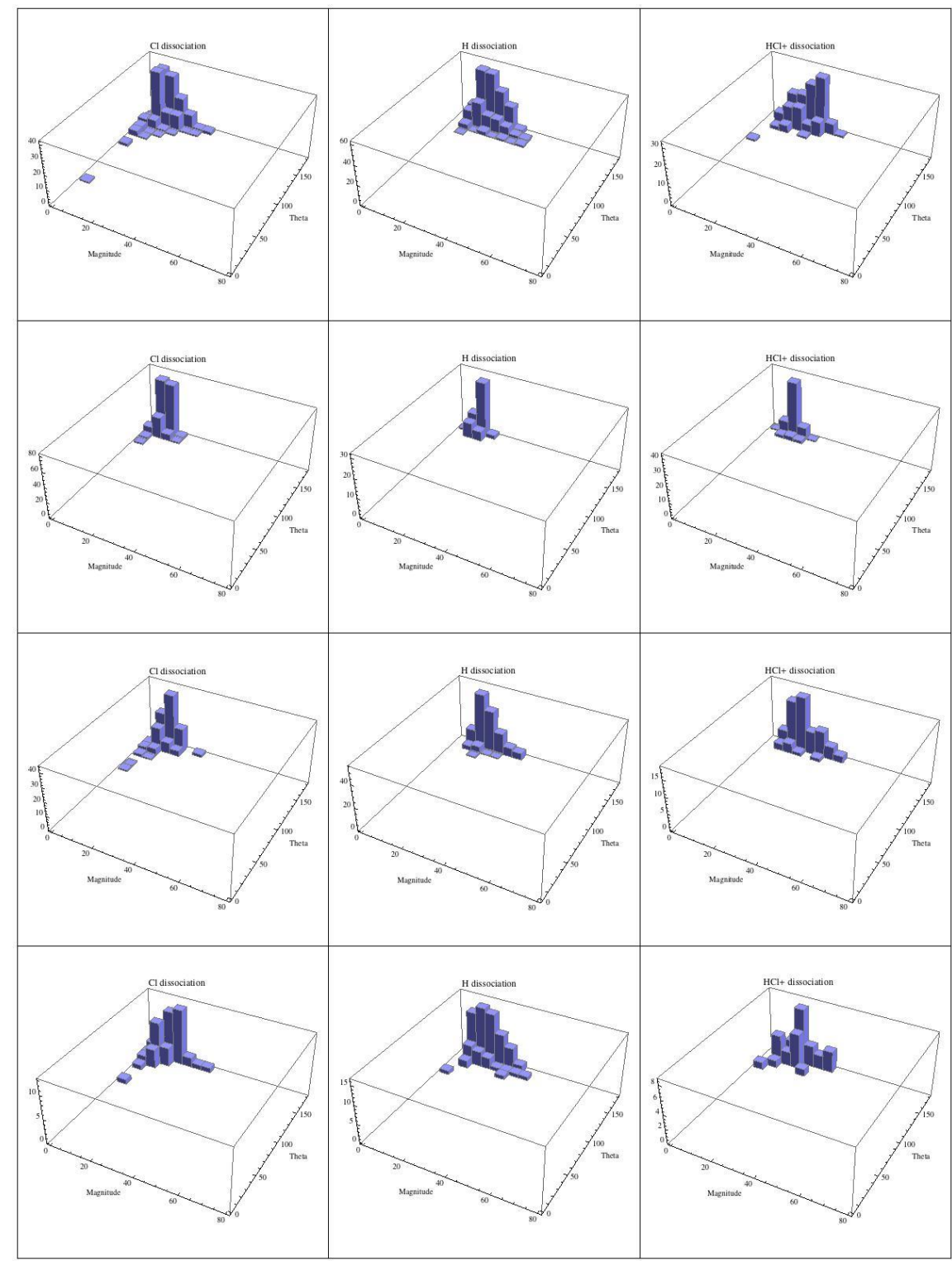

Figure S1. Magnitude and direction of the total angular momentum for the $\mathrm{Cl}+\mathrm{HCO}^{+}, \mathrm{H}+\mathrm{ClCO}^{+}$ and $\mathrm{HCl}^{+}+\mathrm{CO}$ channels for left circularly polarized laser field with trapezoid shape (top row), left circularly polarized laser field with cosine shape (second row), left circularly polarized laser field with $\pi / 2$ phase delay (third row) and left circularly polarized laser field with $\pi / 4$ phase delay.

\section{Decomposition of total angular momentum into fragment contributions}

The total angular momenta can be broken down into the angular momenta of each fragment (Figure S2). Some of the components have a larger range in magnitude than the total angular momentum, indicating there is a significant amount of cancellation. The distributions of the components are qualitatively similar for right and left circularly polarized for the $\mathrm{Cl}+\mathrm{HCO}$ channel and for the $\mathrm{HCl}+\mathrm{CO}$ channel. However, for the $\mathrm{H}+\mathrm{ClCHO}$ channel, there is a clear difference for the internal $\mathrm{ClCO}$ angular momentum: more trajectories have ? 
close to $0^{\circ}$ for right circularly polarized light and close to $180^{\circ}$ for left circularly polarized light, while both $? \approx 0^{\circ}$ and $? \approx 180^{\circ}$ are seen for linearly polarized light. This is primarily because the internal $\mathrm{ClCO}$ angular momentum is the largest component of the total angular momentum for this channel due to this fragment taking up almost the entirety of the molecular mass.

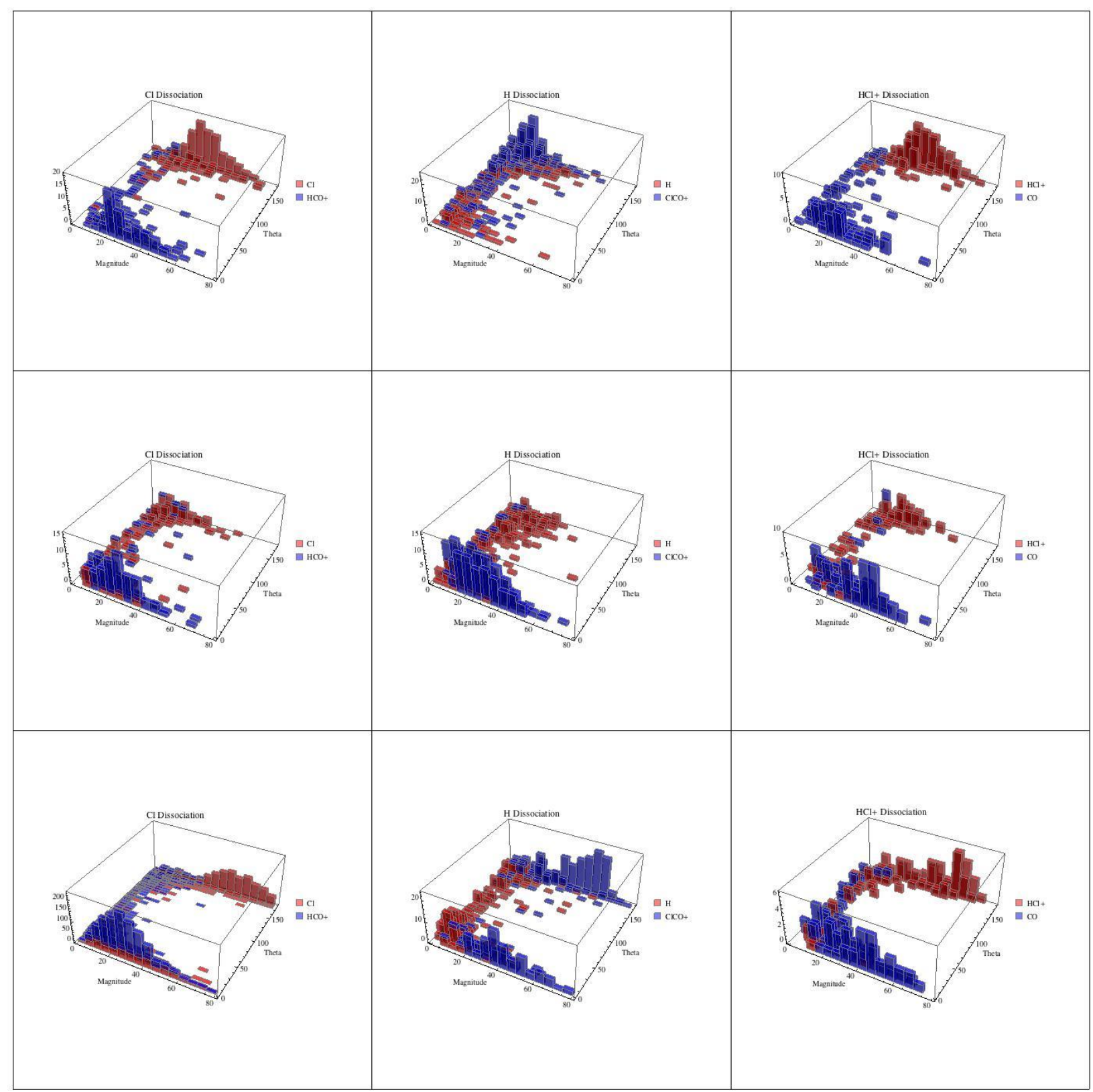

Figure S2. Magnitude and direction of the components of fragmented angular momentum for the $\mathrm{Cl}+\mathrm{HCO}^{+}, \mathrm{H}+\mathrm{ClCO}^{+}$and $\mathrm{HCl}^{+}+\mathrm{CO}$ channels for left circularly polarized light (top row), right circularly polarized light (middle row) and linearly polarized light averaged over $\phi=0-360^{\circ}$. 